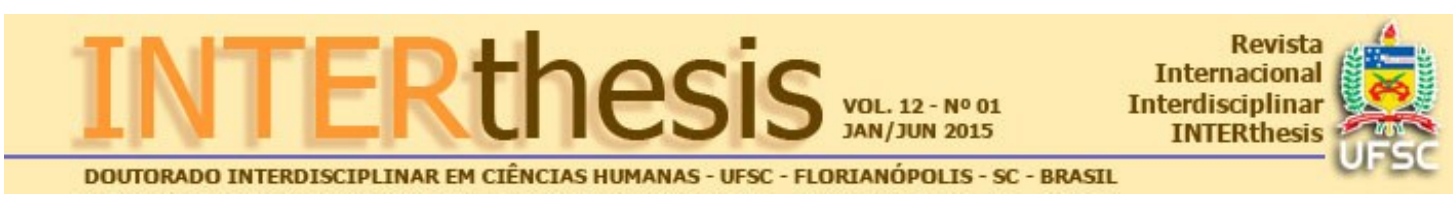

\title{
A CONSTRUÇÃO DO CAMPO DA AGROECOLOGIA E SUA RELAÇÃO COM O DESENVOLVIMENTO RURAL
}

\section{Resumo:}

Paola Maia Lo Sardo ${ }^{1}$

Agroecologia é um termo atualmente apropriado por diferentes grupos e sua conceituação está em constante disputa, carecendo, portanto, uma reflexão crítica de sua história e de seus conceitos fundantes. No presente ensaio procuramos apresentar tal reflexão utilizando como referenciais teóricos a noção de "campo" proposta por Pierre Bourdieu e da discussão de paradigma segundo Thomas Kuhn, uma vez que tal ainda não foi realizada. Também, procuramos pensar como a Agroecologia pode contribuir para o já estabelecido campo do Desenvolvimento Rural. Constatamos a diversidade conceitual que existe na Agroecologia, assim como a falta de clareza em algumas de suas propostas e fundamentos. A Agroecologia relaciona-se diretamente à sustentabilidade e, com isso, leva o Desenvolvimento Rural a repensar seus estilos e processos. Concluímos que a Agroecologia pode efetivamente ser considerada ciência pós-normal, mas o contorno de seu "campo" ainda está em processo de estabelecimento.

Palavras-chave: Paradigma científico. Campo do saber. Sustentabilidade. Ciência pós-normal. Ciência de segunda ordem.

\section{INTRODUÇÃO}

A preocupação em definir o termo Agroecologia e qual é a sua relação com o Desenvolvimento Rural é um tema frequente entre os fundadores da Agroecologia no Brasil. Dentre esses, por exemplo, Francisco Caporal e José Costabeber já colocaram este debate conceitual em pauta na publicação "Agroecologia: alguns conceitos e princípios" (CAPORAL; COSTABEBER, 2004).

Ao longo do presente ensaio, pretendemos retomar este tema e discutir sobre a construção do campo da Agroecologia como ciência a partir da noção de "campo"

\footnotetext{
${ }^{1}$ Mestre em Agroecologia e Desenvolvimento Rural pela Universidade Federal de São Carlos. Professora de Agroecologia no Instituto Federal do Espírito Santo, Campus Santa Teresa, Santa Teresa, ES, Brasil. Email: pmaialosardo@gmail.com

2 Doutor em Ecologia pela Universidade Estadual de Campinas. Professor Adjunto do Departamento de Desenvolvimento Rural do Centro de Ciências Agrárias da Universidade Federal de São Carlos, São Carlos, SP, Brasil. Email: raf@cca.ufscar.br
} 
proposta por Pierre Bourdieu e da discussão de paradigma segundo Thomas Kuhn, assim como sua relação com o Desenvolvimento Rural.

Nos últimos anos, em especial na América Latina, a Agroecologia está se consolidado como um campo científico e acadêmico e este fato pode ser percebido pelo aumento de cursos (técnicos, superiores, pós-graduação) na área e de publicações científicas que se apropriam desse termo (BORSATTO; DO CARMO; 2012). Apesar disso, dentre as/os acadêmicas/os que atuam em Agroecologia são constantes as interpretações de que esta é uma ciência nova e que, por esta razão, as definições não estão completamente consolidadas; que algumas definições são vagas; que não há um conceito definido, pois cada autor ou instituição afirma uma coisa diferente; que é um termo "guarda-chuva" englobando tudo e, ao mesmo tempo, não significando nada. Há, ainda, o uso do termo de forma reducionista, relacionando-o somente às questões técnicas. Mas, será que esta indefinição realmente acontece? O que poderia explicá-la? Isto é positivo ou negativo para a construção do campo da Agroecologia?

\section{DEFINIÇÃO DE CAMPO CIENTÍFICO}

A indefinição sobre o que é a Agroecologia causa insegurança e confusão no campo científico, principalmente para aqueles que estão iniciando na vida acadêmica. Esta confusão não acontece apenas no Brasil, ela está em várias partes do mundo (WEZEl et al., 2009). Neste sentido, Kuhn (2007) enfatiza a importância do estudo dos paradigmas ${ }^{3}$, pois prepara o estudante para ser membro de uma comunidade científica determinada na qual atuará mais tarde. Também Bourdieu (2004) indica que para compreender a arte, a literatura, a ciência etc., não basta referir-se apenas ao conteúdo textual ou ao contexto social, estabelecendo uma relação direta entre eles. Entre estes dois extremos existe um universo

3 "Paradigmas são realizações científicas universalmente reconhecidas que, durante algum tempo, fornecem problemas e soluções modelares para a comunidade de praticantes de uma ciência" (KUHN, 2007, p.13).

R. Inter. Interdisc. INTERthesis, Florianópolis, v.12, n.1, p.337-360, Jan-Jun. 2015 
intermediário: o campo artístico, literário, científico. São mundos sociais como os outros, com agentes e instituições, mas estes microcosmos obedecem a leis sociais mais ou menos específicas.

O campo não escapa às imposições do macrocosmo, ou seja, do global, mas dispõe com relação a este uma autonomia parcial. De acordo com Bourdieu (2004), o grau de autonomia de um campo está relacionado a entender qual a natureza das pressões externas que sofre o campo; a forma sobre a qual elas exercem créditos, ordens, instruções, contratos; e sobre quais formas se manifestam as resistências que caracterizam essa autonomia, ou seja, quais os mecanismos que o campo possui para libertar-se das imposições externas e ter condições de reconhecer apenas suas próprias determinações internas.

As pressões externas ao campo são mediatizadas pela lógica do campo. Assim, quanto mais autônomo for o campo, maior será seu poder de refração e mais as imposições externas serão retraduzidas, a ponto de se tornarem irreconhecíveis. Ao contrário, a heteronomia de um campo manifesta-se quando as questões externas, em especial relacionadas à política, se exprimem diretamente neste campo. Deste modo, a "politização" de um campo não significa grande autonomia (BOURDIEU, 2004).

O capital científico é uma espécie de capital simbólico que consiste no reconhecimento atribuído pelo conjunto de pares-concorrentes no interior de um determinado campo científico. São duas espécies de "capital científico": um social, que é o prestígio, ligado a ocupação de posições importantes nas instituições científicas, e um específico, que é o reconhecimento pelos pares, este último mais exposto à contestação (BOURDIEU, 2004).

Neste sentido, é importante salientar que o campo científico, como qualquer outro, não é neutro, mas é um espaço de disputa, de jogo de poder entre grupos com distintos posicionamentos sociais, não havendo escolha neutra de temas ou métodos, ou seja, a produção do conhecimento está relacionada à percepção e ao posicionamento do cientista diante da realidade social e do seu lugar no campo. Nesta perspectiva, é possível avançar em relação à "ciência pura", totalmente livre 
das necessidades sociais, e a "ciência escrava", sujeita totalmente às demandas político-econômicas (BOURDIEU, 2004).

\section{AGROECOLOGIA COMO CAMPO CIENTÍFICO}

A Agroecologia tem, em suas bases de origem, Klaus Klages, um cientista que investigou e escreveu sobre as atividades agrícolas enfatizando o ponto de vista social (KLAGES, 1928). A geógrafa Susanna Hecht dedicou boa parte de sua carreira científica ao estudo do solo amazônico e de seu deflorestamento, sendo que estes estudos seminais deram origem ao campo da ecologia política, fortalecendo o conceito de Agroecologia (HECHT; COCKBURN, 1990).

Mais recentemente, vários autores como Miguel Altieri, Stephen Gliessman, Eduardo Sevilla-Guzmán, Francisco Caporal e José Antônio Costabeber, entre outros, explicitam suas definições sobre o que é a Agroecologia nos textos científicos, cada um com suas características específicas.

Miguel Altieri e Susanna Hecht foram importantes para a conceituação inicial de Agroecologia que, ao incluírem em suas análises conhecimentos agronômicos, ecológicos, geográficos e antropológicos, a tem como uma forma de abordagem da agricultura na qual existe uma forte preocupação com a natureza e com a sociedade (ALTIERI; HECHT, 1990).

Para Altieri (1995) a Agroecologia é uma ciência que apresenta princípios e metodologias para estudar, analisar, dirigir, desenhar e avaliar agroecossistemas. E afirma:

Agroecologia é, pois, uma ciência, com uma série de princípios; não uma prática ou um sistema de produção. A agricultura orgânica, a agricultura alternativa, a agricultura biodinâmica ou a agricultura natural e outros termos existentes são um conjunto de práticas e tecnologias que permitem a utilização de certos insumos, e não a de outros (ALTIERI, 1995, p.6).

Em outra publicação, este mesmo autor descreve a Agroecologia como um estudo holístico dos agroecossistemas, incluindo todos os elementos ambientais e humanos, com mais atenção sobre a forma, a dinâmica e a função das interrelações e os processos no qual estão envolvidas (ALTIERI, 2001).

R. Inter. Interdisc. INTERthesis, Florianópolis, v.12, n.1, p.337-360, Jan-Jun. 2015 
Gliessman e colaboradores (2002, p.5) definem a Agroecologia "como a aplicação de conceitos e princípios ecológicos para o desenho e manejo de agroecossistemas sustentáveis (...)". Um conceito importante trabalhado por Gliessman é o de agroecossistema, considerado como a unidade fundamental de análise pela Agroecologia, que se baseia no enfoque sistêmico e na Ecologia.

Além disso, Gliessman e colaboradores (2002) afirmam que a sustentabilidade ecológica é o que dá sustentação para a construção das outras dimensões da sustentabilidade (social, econômica etc.) tão importantes quanto à primeira.

No hay disputa sobre el hecho de que para que cualquier agroecosistema sea sostenible, se deben tomar en cuenta una amplia serie de factores y procesos ecológicos, económicos y socales interactuantes. No obstante, la sostenibilidad ecológica es la materia prima de construcción sobre la cual los otros elementos de la sostenibilidad dependen (GLIESSMAN et al., 2002, p.3).

Altieri e Gliessman se destacam pelo enfoque mais ecológico, o que pode ser explicado pela área de atuação de ambos os pesquisadores, que são estudiosos da área de Ecologia. Estes autores buscaram na Ecologia suas abordagens teóricometodológicas, principalmente relacionadas à abordagem sistêmica do meio ambiente, para entender e resolver as questões das Ciências Agrárias.

Paul Wojtkowski é um autor que procura ver a Agroecologia fora dos domínios estritos da Agronomia, colocando-a como uma das grandes divisões da Ecologia. Para ele, então, a Agroecologia é a parte da Ecologia responsável pela compreensão do uso da terra, tendo os seres humanos como a força governante primária para tal (WOJTKOWSKI, 2002).

Para Sevilla-Guzmán (sem ano, p.1), doutor em Sociologia, "A Agroecologia pode ser definida como o manejo ecológico dos recursos naturais através de formas de ação social coletiva que apresentem alternativas para a atual crise civilizatória". Este autor aborda a dimensão social e política de forma mais explícita na definição de Agroecologia.

Diante dessa abordagem, Sevilla-Guzmán (sem ano, p.1) questiona como mudar a estrutura de poder e propõe a organização e a articulação dos atores sociais como formas de resistência. É importante destacar também o conceito de 
potencial endógeno (o conhecimento local e a memória histórica popular), como ponto de partida para o desenvolvimento de sistemas alternativos de produção (SEVILLA-GUZMÁN, sem ano). Neste sentido, Sevilla-Guzmán se refere à Agroecologia como um modo de manejar os recursos naturais e de modificar a estrutura socioeconômica vigente com a participação ativa dos sujeitos envolvidos.

Sobre a definição de Agroecologia apresentada por Sevilla-Guzmán, Borsatto e Do Carmo (2012) comentam que nesta os agricultores são atores centrais nas estratégias de ação da Agroecologia, rompendo com a dicotomia sujeito/objeto, e também se enfrenta a questão da heterogeneidade por meio da valorização do local como portador de um potencial endógeno. E completam:

\begin{abstract}
Agora, a partir do local, passa-se a gerar conhecimentos que podem ser ou não extrapolados para o global, não mais ao contrário, quando se buscava encontrar uma teoria geral para tudo, que abarcasse todas as realidades, sempre na busca de uma homogeneidade inexistente em sistemas socioambientais e culturais. O diferente e o único passam a ter valor (Borsatto e Do Carmo, 2012, p. 713).
\end{abstract}

Outra referência importante é Associação Brasileira de Agroecologia (ABA), que se destina a incentivar e contribuir para a produção de conhecimento científico no campo da Agroecologia, que em seu estatuto apresenta a seguinte definição:

[...] a Agroecologia é entendida como enfoque científico, teórico, prático e metodológico, com base em diversas áreas do conhecimento, que se propõe a estudar processos de desenvolvimento sob uma perspectiva ecológica e sociocultural e, a partir de um enfoque sistêmico, adotando o agroecossistema como unidade de análise, apoiar a transição dos modelos convencionais de agricultura e de Desenvolvimento Rural para estilos de agricultura e de desenvolvimento rural sustentáveis (ASSOCIAÇÃO BRASILEIRA DE AGROECOLOGIA, 2004, art.3º).

William Bland e Michael Bell introduziram o termo "Agroecologia holística", procurando colocá-la em uma noção de intencionalidade e incompletude, dentro de uma infinitude de contextos ecológicos. Assim, a Agroecologia é vista como uma empreitada agrícola que estará constantemente se ajustando aos vários contextos complexos que existirão ao longo do tempo (BLAND; BELL, 2007). Assim sendo, tais autores estão integrados em um arcabouço pós-moderno (pós-estruturalista) de compreensão do campo, que é percebido como incompleto, não unificado, não finito.

Mais recentemente, Gliessman (2007) publica um importante livro "Agroecology: the ecology of sustainable food systems", no qual afirma que a 
Agroecologia é a aplicação de conceitos e princípios ecológicos para o desenho e manejo de sistemas alimentares sustentáveis, ampliando a escala de atuação da Agroecologia para além dos agroecossistemas, incluindo toda a sociedade, desde os agricultores até os consumidores. Assim, a Agroecologia não se refere apenas ao ambiente rural, mas engloba toda sociedade.

Neste sentido, a Agroecologia está sendo pensada como uma ciência de segunda ordem, ou seja, aquela que pode analisar, através de seus princípios e métodos baseados na interdisciplinaridade, problemas complexos como as crises alimentares, a mitigação das mudanças climáticas e o desenvolvimento sustentável (ALRøE; NOE, 2014).

Muitas das definições aqui citadas já afirmam a Agroecologia como ciência e também como um novo paradigma para o desenvolvimento rural, entretanto, destaca-se que esses autores falam do interior do campo agroecológico.

Além, disso, existem muitas semelhanças conceituais entre os autores abordados aqui, como: considerar as dimensões ecológica, cultural, econômica e social para compreensão da realidade; a visão sistêmica e holística; a Agroecologia como estratégia para alcançar formas alternativas de produção e reorganização da sociedade para o enfrentamento da crise socioambiental; a mínima dependência de insumos e energia externos nos sistemas de produção; apostar em sistemas produtivos mais complexos; em propostas participativas e coletivas; propostas agroecológicas em longo prazo; o diálogo de saberes, tendo a valorização do conhecimento local e tradicional. Esses pontos em comum, portanto, compreendem os principais aspectos que definem o campo da Agroecologia, ou seja, podemos dizer que são princípios agroecológicos.

Apesar das aproximações, cada autor apresentado tem uma perspectiva própria para abordar e conceituar a Agroecologia, dependendo do lugar que ocupa no campo, do seu reconhecimento e da sua formação/atuação. Como mencionado anteriormente, o campo é um espaço de disputa e jogo de poder entre grupos com distintos posicionamentos sociais (BOURDIEU, 2004). Deste modo, consideramos de extrema importância as diversas definições, pois cada pesquisador/sujeito 
contribui para a construção do conhecimento agregando diferentes abordagens, que, neste caso, se complementam.

Neste contexto, a Ecologia foi um dos eixos científicos que mais influenciou a emergência da Agroecologia no campo científico (ALTIERI, 2001). Mas apenas um ramo da ciência não é suficiente para construção do campo da Agroecologia, que se pretende uma ciência transdisciplinar, necessitando não apenas da contribuição de diversas áreas do conhecimento, mas de diferentes saberes.

Também podemos dizer que a Agroecologia, assim como Kuhn (2007) se referiu à bioquímica, surgiu da divisão e combinação de especialidades já amadurecidas. Além da Ecologia, as Ciências Sociais (principalmente a Sociologia), a Economia, as Ciências Agrárias e as Florestais, a História, a Geografia, a Educação Popular compõe os conhecimentos agroecológicos. Além disso, como afirmam Altieri (2001), Gliessman e colaboradores (2002) e Sevilla-Gúzman (sem ano), a Agroecologia agrega outras formas de conhecimentos (locais e tradicionais), além dos acadêmicos:

La evidencia empírica obtenida durante las cuatro últimas décadas desde la Agroecología (Altieri, 1985; Gliessman, 1998; Guzmán Casado, Gonzalez de Molina y Sevilla Guzmán, 2000) ha demostrado que el conocimiento acumulado sobre los agroecosistemas en el pasado puede aportar soluciones específicas de cada lugar para resolver los problemas sociales y medioambientales (SEVILLA GÚZMAN, p. 1, sem ano).

Assim, a Agroecologia articula o tradicional, com sustentabilidade histórica, com o novo (SEVILLA-GUZMÁN, 2001). Como bem resumem Caporal e Costabeber (2004, p.13):

[...] a Agroecologia se consolida como enfoque científico na medida em que este campo de conhecimento se nutre de outras disciplinas científicas, assim como de saberes, conhecimentos e experiências dos próprios agricultores, o que permite o estabelecimento de marcos conceituais, metodológicos e estratégicos com maior capacidade para orientar não apenas o desenho e manejo de agroecossistemas sustentáveis, mas também processos de desenvolvimento rural sustentável.

Portanto, há uma diversidade de definições e enfoques para Agroecologia no campo científico, sendo que algumas nem foram aqui mencionadas. Mas aquelas que foram apresentadas neste texto, de certa forma convergem e se complementam, umas mais relacionadas às questões ecológicas, outras às 
socioeconômicas, umas com caráter mais analítico, outras mais relacionadas às aplicações, umas com estudos focados nos agroecossistemas, outras com um enfoque mais global. Isso pode ser explicado, como será discutido mais adiante, devido à construção de um paradigma.

Mesmo agregando vários conhecimentos e campos, a Agroecologia pode ser considerada um campo específico de produção do conhecimento, pois um campo de estudos pode tornar-se uma ciência (KUHN, 2007). Todo campo científico, por mais consagrado, está sempre em construção, pois a ciência não é algo acabado, mas se modifica permanentemente. A sociedade também está constantemente se transformando e precisa que a ciência a acompanhe, para tentar explicar a realidade e, de alguma forma, ajudar a resolver algumas questões. Além disso, um campo pode se aproximar, ou seja, possuir intersecções com outros campos (Figura 1). E esta relação vai se modificando ao longo do tempo.

Neste ensaio o enfoque maior foi dado à Agroecologia como ciência, mas é importante ressaltar que a Agroecologia pertence também ao campo científico, não negando que ela pode pertencer a outros campos Wezel e colaboradores (2009, p.1) afirmam que: "Today, the term 'agroecology' means either a scientific discipline, agricultural practice, or political or social movement.".

Figura 1. Diagrama de intersecção entre os campos científicos que contribuem para a construção do campo da Agroecologia.

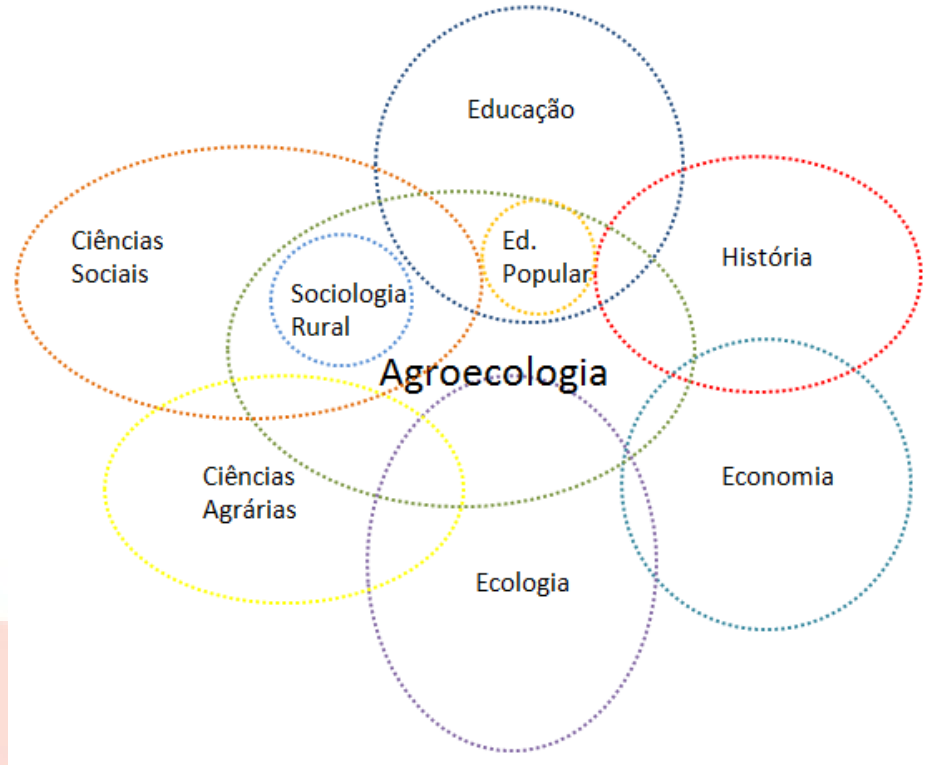

R. Inter. Interdisc. INTERthesis, Florianópolis, v.12, n.1, p.337-360, Jan-Jun. 2015 
Fonte: Elaborado pelos autores.

Além da discussão de formação do campo científico e suas disputas internas e externas, podemos analisar a Agroecologia segundo a noção de construção da ciência, a partir da definição de paradigma, proposta por Kuhn (2007, p.221): "Um paradigma é aquilo que os membros de uma comunidade partilham e, inversamente, uma comunidade científica consiste em homens que partilham de um paradigma".

O paradigma orienta a pesquisa, desse modo, a comunidade científica ao adquirir um paradigma adquire igualmente um critério para a escolha de problemas, que enquanto o paradigma for aceito, podem ser considerados como dotados de uma solução possível (KUHN, 2007).

Existe um período chamado de pré-paradigmático que é marcado por debates frequentes e profundos a respeito de métodos, problemas e padrões de solução legítimos, embora estes debates sirvam mais para definir escolas do que para produzir um acordo. Depois de aceito o paradigma, o campo se dedica mais a problemas de natureza interna (KUHN, 2007).

O que faz uma comunidade científica buscar novos paradigmas é geralmente a crise diante do paradigma vigente, que não mais resolve os problemas colocados. Decidir rejeitar um paradigma é decidir simultaneamente aceitar outro e o juízo que conduz a essa decisão envolve a comparação de ambos os paradigmas com a natureza, bem como sua comparação mútua (KUHN, 2007).

Não há dúvida de que a agricultura passa por crises que consequentemente refletem nas Ciências Agrárias. No entanto, há divergências em relação às suas causas, devido, principalmente, às trajetórias e experiências dos pesquisadores/sujeitos. Parece-nos, no entanto, que a atual crise é civilizatória, surgida após o advento do capitalismo, da visão positivista de ciência, da era industrial e da tecnocracia, conforme apontam alguns autores como: Baudrillard, 2007; Beck, 1998; Engels, 1987; Ehlers, 1996; Featherstone, 1997 e Leis, 1999.

Borsatto e Do Carmo (2012, p. 711) afirmam que:

A Agroecologia emerge no campo cientifico como uma resposta à crise socioambiental que o mundo rural vem atravessando, para a qual as disciplinas convencionais não conseguem encontrar respostas; mais do que 
isso, se percebe que foram essas mesmas disciplinas que contribuíram para o fomento da crise.

A Agroecologia questiona grande parte dos paradigmas dominantes, mas esta já pode ser considerada um paradigma? Será que no campo da Agroecologia existem vários paradigmas? Será que a Agroecologia está passando por um período pré-paradigmático, já que a Agroecologia é uma ciência relativamente nova? A Agroecologia ainda se ocupa bastante de discussões como esta que está sendo colocada no presente ensaio, será por pressão de outros campos do conhecimento ou porque está em um período de construção de seu(s) paradigma(s)?

Já podemos perceber uma comunidade científica -como dito anteriormente o aumento de cursos de Agroecologia nos diversos níveis e o crescente número de publicações científicas- e até diferentes escolas identificadas, se dedicando exclusivamente ao campo da Agroecologia, mas talvez seja pretensioso avaliar que a Agroecologia tem um paradigma já "consolidado".

Borsatto e Do Carmo (2012) apontam que a teoria do pensamento complexo, proposta por Edgar Morin, pode se constituir em um arcabouço filosófico onde a Agroecologia pode se assentar com o objetivo de estabelecer um novo paradigma para se abordar o desenvolvimento do meio rural.

Diante de nossa breve experiência no campo, arriscamo-nos a dizer que o paradigma da Agroecologia ainda está em construção por ser uma ciência nova e que ainda não conseguimos perceber a construção de diferentes paradigmas dentro do campo, apesar de algumas divergências observadas.

Neste sentido, não há no presente momento como responder às questões colocadas acima. Esta análise só será possível com o passar do tempo, com um estudo histórico da Agroecologia, ou seja, estudos relacionados à história desta ciência, como já foi realizado com diversas ciências mais antigas. De qualquer forma, a Agroecologia poderia ser considerada uma ciência pós-normal, uma vez que derivada e distanciada das ciências agronômica e ecológica.

Outra questão é que, além da diversidade de definições e da construção do(s) paradigma(s), há muita confusão, sendo que o termo Agroecologia é usado com alguns equívocos conceituais. Esses podem prejudicar o avanço da Agroecologia,

R. Inter. Interdisc. INTERthesis, Florianópolis, v.12, n.1, p.337-360, Jan-Jun. 2015 
pois geram interpretações que prejudicam o entendimento da Agroecologia como ciência que estabelece bases para a construção de agriculturas sustentáveis e de estratégias de Desenvolvimento Rural Sustentável (CAPORAL; COSTABEBER, 2004).

Apesar de reconhecermos a Agroecologia como ciência, movimento e prática (WEZEL et al, 2009), a Agroecologia não pode ser reduzida a um modelo ou um tipo de agricultura, ou seja, uma forma de produzir. Ou a um termo para se referir a oferta de produtos "limpos" ou "ecológicos", em oposição aos produzidos pelo pacote da Revolução Verde. Estas visões errôneas da Agroecologia estão relacionadas apenas às questões técnicas ou agronômicas e às de mercado, respectivamente (CAPORAL; COSTABEBER, 2004). Neste sentido, como um campo científico, a Agroecologia deve ter um caráter preferencialmente analítico e não normativo. Para exemplificar, no caso da Agricultura Orgânica como se encontra hoje no Brasil, que é uma forma de produção agrícola com normas a serem seguidas, seu caráter neste contexto é estritamente técnico e normativo.

Além disso, as apropriações do termo para fins de mercado, "marketing ecológico", como acontece com outros termos, como a sustentabilidade, também merecem atenção e devido esclarecimento.

Também é importante salientar que o caminho tomado pela Agroecologia difere em diferentes culturas, como o é no Brasil e em outros países (WEZEL et al, 2009). No Brasil a Agroecologia inicia como prática e movimento, surgindo por meio das práticas de agricultura tradicionais e movimentos de base, e não como ciência:

\begin{abstract}
In summary, agroecology in Brazil was first a movement for rural development and environmental aspects in agriculture. This stimulated a search for alternative practices, now more often called agroecological practices, which were also related to the dynamics of organic farming. In recent years, agroecology has also been considered a scientific discipline,based on an adaptation of the U.S. scientific interpretation of agroecology with an integration of social dimensions (WEZEL et al., 2009, p. 508).
\end{abstract}

Diante disso, outro aspecto relacionado ao grau de autonomia do campo, como alerta Bourdieu, é a relativa influência de questões políticas. Isto acontece na Agroecologia, que, como afirmado anteriormente, vai além da ciência, sendo 
considerada também como prática e movimento. O que era de se esperar, já que é um campo que se relaciona com a sociedade, que trabalha com as comunidades e os movimentos sociais. Outra questão é a projeção da Agroecologia nos demais campos, como as Ciências Agrárias, que vêm crescendo nas últimas décadas, mas ainda de forma tímida.

Concluindo, tomamos aqui o que Afrânio Catani indicou para a Educação Ambiental, esta também derivada de outras ciências e com forte interface social como o é a Agroecologia:

Talvez se possa dizer que meio ambiente, e a educação ambiental em particular, se não é um campo, constitui-se em um subcampo, quer dizer, é uma área em processo de legitimação: tem agentes, alunos, professores, cursos, áreas de concentração, já possui produção significativa, há um ministério equivalente. E tem algo que é fundamental na reprodução de um campo, que é a criação de toda uma estrutura, que eu acho que vai permanecer, através da qual se preparam e se formam pessoas para formar outras pessoas, que irão trabalhar com meio ambiente (CATANI, 2009, p. 42).

\section{AGROECOLOGIA, CAMPESINATO E DESENVOLVIMENTO RURAL}

Até meados da década de 1990, existia um debate na chamada Sociologia da Agricultura entre duas correntes: o marxismo chayanoviano e a economia e sociologia política leninista (variante atual do marxismo ortodoxo). A primeira corrente afirmava que a agricultura familiar possuía mecanismos de resistência para manter sua natureza socioeconômica. Ao contrário, a segunda, acreditava no desaparecimento da agricultura familiar com o desenvolvimento do capitalismo (ABRAMOVAY, 1998; LAZZARETTI, 2007; SEVILLA-GUZMÁN; MOLINA, 2005).

No entanto, ao contrário do que pensavam os leninistas sobre o fim do campesinato, este se manteve ao longo da história devido ao seu potencial de adaptação e resistência. Segundo Chayanov, a economia familiar não sobrevive apenas por meio do próprio empobrecimento, mas também se utiliza de algumas características da agricultura e da vida social rural que podem proporcionar vantagens a economias não capitalistas sobre as formas de produção capitalistas,

R. Inter. Interdisc. INTERthesis, Florianópolis, v.12, n.1, p.337-360, Jan-Jun. 2015 
ambas inseridas no contexto do capitalismo (SHANIN, 1988, citado por SEVILLAGUZMÁN; MOLINA, 2005).

As origens da crise da agricultura na América Latina são históricas e remontam aos tempos coloniais, quando as populações tradicionais foram expulsas de suas terras (ROSSET, 2007). Com a Revolução Verde, a industrialização da agricultura, a entrada de capital industrial no campo e a agricultura voltada para a exportação, ocorreu o agravamento das condições de vida dos camponeses (QUEIROZ; SILVA, 2007) e uma crescente desconexão entre a produção agropecuária e as condições locais como: as peculiaridades da força de trabalho, a elaboração de produtos com características culturais e regionais específicas e a articulação das formas autônomas de organização do trabalho (NORDER, 2006), tornando-se necessário repensar os estilos de Desenvolvimento Rural.

Neste sentido, as características da agricultura e da vida social rural que conferem vantagens aos camponeses são chamadas de potencial endógeno. Este possui duas dimensões, uma ecológica e outra social. A dimensão ecológica é representada pela agricultura de baixas entradas, pela escala de produção, pela base energética e pelos agroecossistemas. Já a dimensão social é representada pela: força e organização social do trabalho, identidade local, autonomia, cooperação e outras formas de ação social coletiva (CASADO; SEVILLA-GUZMÁN; MOLINA, 2000).

Neste sentido, Shanin (1988, citado por SEVILLA-GUZMÁN; MOLINA, 2005) destaca, na proposta teórica de Chayanov, o conceito de ótimos diferenciais como a possibilidade do conhecimento local ser um elemento gerador de tecnologias autóctones, capaz de captar o potencial endógeno dos recursos naturais, ou seja, pode-se identificar o campesinato como categoria integrada a um específico modo de uso dos recursos naturais (GUHA; GADGIL, 1993; TOLEDO, 1995, citados por SEVILLA-GUZMÁN; MOLINA, 2005).

Assim, as culturas tradicionais, contrastando com os modernos sistemas de produção, tendem a implementar e desenvolver sistemas ecologicamente corretos para a utilização dos recursos naturais. Deste modo, acredita-se que exista uma 
racionalidade ecológica na produção tradicional (TOLEDO, 1990, citado por SEVILLA-GUZMÁN; MOLINA, 2005).

Portanto, o enfoque agroecológico visa despertar o potencial endógeno gerando processos que revelem novas respostas ou façam surgir às antigas (SEVILLA-GUZMÁN, 2001), a partir desta relação estreita com o campesinato e agregando contribuições de diversos campos do conhecimento.

Van der Ploeg (2009) sustenta que a agricultura camponesa apresenta-se indispensável para a produção de alimentos, renda e emprego, contribuindo de forma imprescindível para o desenvolvimento rural. Assim sendo, o modo de produção camponês não seria uma mera volta ao passado das culturas tradicionais, mas sim a possibilidade viável de um desenvolvimento rural sustentável, uma vez que é baseada no capital ecológico. A importância do capital ecológico é assim indicada por Jan Douwe van der Ploeg:

Consequentemente, a produção camponesa visa: a) a reprodução, a melhoria e a ampliação do capital ecológico; b) a produção de excedentes comercializáveis (por meio do uso do capital ecológico disponível); e c) a criação de redes e arranjos institucionais que permitam tanto a produção como sua reprodução (van der PLOEG, 2009, p. 20).

No Brasil, o PRONAF (Programa Nacional de Fortalecimento da Agricultura Familiar), de 1996, aposta no reconhecimento e fortalecimento da agricultura camponesa. Porém, como bem expressa Hespanhol (2008): "os desafios da geração de renda e da reprodução social dos pequenos agricultores persistem e não há indicações claras de que tais desafios serão superados a curto e médio prazo".

Guadarrama-Zugasti, Trujillo-Ortega e Ramírez-Miranda (2009) destacam que uma das características da atual discussão sobre o desenvolvimento rural é a participação de diferentes campos de pensamento, contribuindo com uma pluralidade de embasamentos epistemológicos, enfoques e métodos. A agricultura passa a ser, então, apenas uma das dimensões do meio rural, da ruralidade (MARTINS, 2014).

A noção de desenvolvimento territorial rompe com a dualidade entre rural e urbano, que segundo Carneiro $(2014$, p. 32), "permite romper, com a inoperante dualidade entre o rural e o urbano que tem se demonstrado limitada e insuficiente

R. Inter. Interdisc. INTERthesis, Florianópolis, v.12, n.1, p.337-360, Jan-Jun. 2015 
para dar conta da realidade das sociedades contemporâneas". Nesta noção, o papel da agricultura não é apenas a de produzir e fornecer alimentos, mas também a manutenção da biodiversidade, do incremento dos serviços ambientais e da possibilidade de uma multifuncionalidade sustentável do meio rural. Sustenta Maria José Carneiro:

Em um país onde é grande o número de residentes no meio rural que não têm condições, por diferentes motivos, de desenvolver uma agricultura comercialmente competitiva, nem de viver somente da atividade agrícola, a noção de multifuncionalidade permite reconhecer, estimular e valorizar formas de inserção social dessa população, resgatando-lhe também o sentido de cidadania (CARNEIRO, 2014, p. 46).

Molina (2009), apesar de concordar sobre a incontestável pertinência do enfoque agroecológico para o desenvolvimento rural sustentável, alerta que as experiências existentes se resumem àquelas restritas a determinadas propriedades ou comunidade locais, que não procuram eventuais conexões ou replicabilidade entre si. Assim sendo, há a necessidade da Agroecologia avançar em suas análises e reflexões de caráter mais geral.

E ainda Molina (2009) apresenta uma alternativa para avançar neste aspecto: a emergência de uma Agroecologia Política, na qual o enfoque agroecológico concede uma maior atenção aos aspectos políticos para desenhar as melhores estratégias de alcançar a sustentabilidade e a reversão da atual crise mundial. A construção dessa vertente da agroecologia está em pleno desenvolvimento a partir da contribuição dos movimentos sociais do campo no Brasil, como indica Sílvio Gomes de Almeida:

A construção de alianças estratégicas entre movimentos sociais e organizações da sociedade civil - tanto no meio urbano quanto no rural apresenta-se assim como crucial para o fortalecimento da capacidade política da sociedade para expressar e defender um projeto nacional de desenvolvimento que compatibilize as políticas macroeconômicas com as políticas de desenvolvimento rural numa perspectiva de promoção da sustentabilidade socioambiental. Além de ser imperativa para que o enfoque agroecológico faça seu caminho e se amplie como movimento social, a mobilização desses mediadores coletivos torna necessária a atualização dos conceitos e métodos até então trabalhados pela expressão pública da Agroecologia (ALMEIDA, 2009, p. 81).

R. Inter. Interdisc. INTERthesis, Florianópolis, v.12, n.1, p.337-360, Jan-Jun. 2015 
Sendo assim, como observado por Wezel e colaboradores (2009) em relação ao desenvolvimento histórico do termo Agroecologia, esta irá contribuir para o desenvolvimento rural uma vez que se reconheçam os seus três componentes históricos- ciência, movimento e prática-, que juntos podem contribuir para a superação da crise e para o desenvolvimento de uma sociedade mais justa e saudável. Ademais, a Agroecologia deve ser vista numa escala ampliada quando se fala na superação da crise civilizatória, passando do agroecossistema para os sistemas agroalimentares, incluindo o urbano em suas transformações. É necessário este movimento do local para o global, da parte para o todo, do rural para o urbano e vice-versa. Não há como transformar o rural, excluindo o urbano. Logo, este conceito de desenvolvimento rural pode ser superado, passando para o desenvolvimento territorial, visando à sustentabilidade dos sistemas agroalimentares.

Uma segunda alternativa para o avanço é a recente construção do embasamento teórico-metodológico da Agroecologia como uma ciência de segunda ordem (ALRØE; NOE, 2014). Esse enquadramento científico, que pode dar conta de aglutinar e analisar diferentes dimensões da ruralidade e diferentes perspectivas epistemológicas em uma abordagem interdisciplinar, ao ser aplicado à compreensão do desenvolvimento rural brasileiro poderá indicar a potencialidade da Agroecologia no delineamento do desenvolvimento rural sustentável. Essa poderá ser uma importante contribuição da Academia, como uma das forças que compõe os diversos setores da sociedade na construção da agroecologia e do desenvolvimento rural sustentável.

\section{CONSIDERAÇÕES FINAIS}

A Agroecologia pode ser considerada um campo específico de produção do conhecimento, que está no início de sua construção acadêmica. Esta construção é permanente, pois a ciência não é algo acabado e se modifica constantemente.

Diante da atual crise civilizatória, o campo da Agroecologia - considerada como ciência, movimento e prática- está sendo construído em contraponto aos paradigmas

R. Inter. Interdisc. INTERthesis, Florianópolis, v.12, n.1, p.337-360, Jan-Jun. 2015 
dominantes, mas talvez seja pretensioso avaliar que a Agroecologia tenha um paradigma próprio já "consolidado".

Os diferenciais da Agroecologia na construção do conhecimento são o diálogo de saberes e a valorização do local, que permitem a interpretação da realidade de forma complexa e coloca os atores sociais como participantes desta construção.

Por fim, a Agroecologia, como ciência, tem um significado amplo relacionado diretamente à sustentabilidade e as suas seis dimensões (social, ecológica, econômica, cultural, política e ética) que nos leva a repensar, dentro desta perspectiva da sustentabilidade, os estilos de desenvolvimento que desejamos nos dias atuais, visando à sustentabilidade dos sistemas agroalimentares.

R. Inter. Interdisc. INTERthesis, Florianópolis, v.12, n.1, p.337-360, Jan-Jun. 2015 


\title{
THE CONSTRUCTION OF AGROECOLOGY FIELD AND ITS RELATION TO RURAL DEVELOPMENT
}

\begin{abstract}
Agroecology is a term currently appropriated by different groups and its conceptualization is in constant dispute, lacking therefore a critical reflection of its history and its foundational concepts. In this essay we try to present this reflection using as theoretical references the notion of "field" proposed by Pierre Bourdieu and the discussion of paradigm according to Thomas Kuhn, since this has never been done. Also, we tried to think how agroecology can contribute to the already established field of Rural Development. It was noted the conceptual diversity that exists in agroecology, as well as the lack of clarity in some of their proposals and fundamentals. Agroecology is directly related to sustainability and thereby leads rural development to rethink its styles and processes. It was concluded that agroecology can effectively be considered post-normal science, but the outline of its "field" is still in process of establishment.
\end{abstract}

Keywords: Scientific paradigm. Field of knowledge. Sustainability. Post-normal science. Second order science.

\section{LA CONSTRUCCIÓN DEL CAMPO DE LA AGROECOLOGÍA Y SU RELACIÓN CON EL DESARROLLO RURAL}

\section{Resumen}

Agroecología es un término actualmente apropiado por diferentes grupos y su conceptuación está en constante disputa, careciendo, por lo tanto, de una reflexión crítica de su historia y sus conceptos fundadores. En este ensayo tratamos de presentar esta reflexión utilizando como referenciales teóricos la noción de "campo" propuesta por Pierre Bourdieu y la discusión de paradigma según Thomas Kuhn, ya que esto todavía no se ha hecho. Además, tratamos de pensar como la Agroecología puede contribuir al ya establecido campo del Desarrollo Rural. Constatamos la diversidad conceptual que existe en Agroecología, así como la falta de claridad en algunas de sus propuestas y fundamentos. La Agroecología se relaciona directamente a la sostenibilidad y, con eso, exige que el Desarrollo Rural repiense sus estilos y procesos. Concluimos que la Agroecología puede efectivamente ser considerada ciencia post-normal, pero el contorno de su "campo" está aún en proceso de establecimiento.

Palabras-clave: Paradigma científico. Campo de conocimiento. Sustenibilidad. Ciencia post-normal. Ciencia de segundo orden. 


\section{AGRADECIMENTOS}

Nossos agradecimentos a dois revisores anônimos da INTERthesis que muito contribuíram para a melhoria da versão preliminar desse artigo, assim como a Luiz Antonio Cabello Norder que motivou a reflexão inicial sobre a importância da agroecologia no desenvolvimento rural e a Egon Noe que, em palestra proferida no Programa de Pós-Graduação em Agroecologia e Desenvolvimento Rural da Universidade Federal de São Carlos, expôs a recente compreensão da agroecologia como uma ciência de segunda ordem.

R. Inter. Interdisc. INTERthesis, Florianópolis, v.12, n.1, p.337-360, Jan-Jun. 2015 


\section{REFERÊNCIAS}

ABRAMOVAY, R. O admirável mundo novo de Alexander Chayanov. Estudos Avançados, v.12, n. 32, p. 69-74, 1998.

ALMEIDA, S. G. Construção e desafios do campo agroecológico brasileiro. In: PETERSEN, P. (org.) Agricultura familiar camponesa na construção do futuro, p. 67-83. Rio de Janeiro: AS-PTA, 2009.

ALRØE, H. F.; NOE, E. Second-order science of interdisciplinary research: A polyocular framework for wicked problems. Constructivist Foundations, v. 10, n. 1, p. 65-76, 2014.

ALTIERI, M. A. Agricultura sustentável. (Entrevista) Jaguariúna/SP, v. 2, n. 2, p. 5$1,1995$.

ALTIERI, M. A. Agroecología: principios y estrategias para diseñar sistemas agrarios sustentables. In: ALTIERI, M.A., Agroecología: principios y estratégias para diseñar una agricultura que conserva recursos naturales y asegura la soberanía alimentaria, p. 27-34, 2001.

ALTIERI, M. A.; HECHT, S. B. Agroecology and small farm development. Michigan: CRC Press, 1990.

ABA- ASSOCIAÇÃO BRASILEIRA AGROECOLOGIA. Estatuto da Associação Brasileira Agroecologia, 2004. Disponível em: http://abaagroecologia.org.br/wordpress/wp-content/uploads/2013/06/Estatuto-ABA.pdf. Acesso em: 20 de jun. 2012.

BAUDRILLARD, J. A sociedade de consumo. 2. ed. Lisboa: Edições 70, 2007.

BECK, U. La sociedad del riesgo. Barcelona: Ediciones Paidós Ibérica, 1998.

BLAND, W. L.; BELL, M. M. A holon approach to agroecology. International Journal of Agricultural Sustainability, v. 5, n. 4, p. 280-294, 2007. 
BORSATTO, R. S.; DO CARMO, M. S. Agroecologia e sua epistemologia.

Interciência, vol. 37, n. 9, p.711-716, 2012.

BOURDIEU, P. Os usos sociais das ciências. Por uma sociologia clínica do campo científico. Trad. CATANI, D. B. São Paulo: Editora UNESP, 2004.

CAPORAL, F. R.; COSTABEBER, J. A. Agroecologia: alguns conceitos e princípios. Brasília: MDA/SAF/DATER-IICA, 2004.

CARNEIRO, M. J. "Desenvolvimento territorial sustentável": o retorno ou a morte do camponês? In: MARTINS, R. C. (org.) Ruralidades, trabalho e meio ambiente, $p$. 31-47. São Carlos: EdUFSCar, 2014.

CASADO, G. G.; SEVILLA-GUZMÁN, E.; MOLINA, M. G. Introducción a la agroecología como desarrollo rural sostenible. Madrid: Mundi-Prensa, 2000.

CATANI, A. Configuração do campo de pesquisa em educação ambiental. Pesquisa em Educação Ambiental, v. 4, n. 2, p. 27-47, 2009.

EHLERS, E. Agricultura sustentável: origens e perspectivas de um novo paradigma. São Paulo: Livros da Terra, 1996.

ENGELS, F. A origem da família, da propriedade privada e do Estado. 11 ed. Rio de Janeiro: Civilização Brasileira, 1987.

FEATHERSTONE, M. O desmanche da cultura: globalização, pós modernidade e identidade. São Paulo: Studio Nobel/SESC, 1997.

GLIESSMAN, S.R. et al. Agroecología: un enfoque sustentable de la agricultura ecológica: ¿qué es la agroecología? Lectura № 2-1 Del Modulo De Trabajo Personal: Programa Interuniversitario Oficial de Posgrado, 2002.

GLIESSMAN S.R. Agroecology: the ecology of sustainable food systems. CRC Press: Taylor \& Francis, New York, USA, 2007. 
GUADARRAMA-ZUGASTI, C.; TRUJILLO-ORTEGA, L.; RAMÍREZ-MIRANDA, C. Agroecologia e desarrollo rural en Mexico: bases agroecológicas, sistemas sostenibles y soberanía alimentaria. In: SAUER, S.; BALESTRO, M. V.

Agroecologia e os desafios da transição agroecológica, p. 101-140. São Paulo: Expressão Popular, 2009.

HECHT, S.; COCKBURN, A. The fate of the forest: developers, destroyers and defenders of the Amazon. New York: Harpercollins, 1990.

HESPANHOL, A. N. Desafios da geração de renda em pequenas propriedades e a questão do desenvolvimento rural sustentável no Brasil. In: ALVES, A. F.; CARRIJO, B. R.; CANDIOTTO, L. Z. P. Desenvolvimento territorial e agroecologia, p. 81-93. São Paulo: Expressão Popular, 2008.

KLAGES, K. H. W. Crop ecology and ecological crop geography in the agronomic curriculum. J. Amer. Soc. Agron. v. 20, p. 336-353, 1928.

KUHN, T. S. A estrutura das revoluções científicas. Trad. BOEIRA, B. V.; BOEIRA, N. 9 ed. São Paulo: Perspectivas, 2007.

LAZZARETTI, M. A. Lênin, o campesinato e o MST. Tempo da Ciência, v. 14, n.28, p. 131-142, 2007.

LEIS, H. R. A modernidade insustentável: as críticas do ambientalismo à sociedade contemporânea. Petrópolis: Vozes, 1999.

MARTINS, R. C. Pensando as ruralidades contemporâneas. In: MARTINS, R. C. (org.) Ruralidades, trabalho e meio ambiente, p. 7-12. São Carlos: EdUFSCar, 2014.

MOLINA, M. G. Las experiencias agroecológicas y su incidencia en el desarrollo rural sostenible. La necesidad de una agroecología política. In: SAUER, S.; BALESTRO, M. V. Agroecologia e os desafios da transição agroecológica, $p$. 17-70. São Paulo: Expressão Popular, 2009. 
NORDER, L. A. C. Mercantilização da agricultura e desenvolvimento territorial. In: Schneider, S. A Diversidade da Agricultura Familiar. 2 ed. Porto Alegre: Ed. UFRGS, 2006.

van der PLOEG, J. D. Sete teses sobre a agricultura camponesa. In: PETERSEN, P. (org.) Agricultura familiar camponesa na construção do futuro, p. 17-31. Rio de Janeiro: AS-PTA, 2009.

QUEIROZ, J. B. P.; SILVA, L. H. Formação de alternância e desenvolvimento rural no Brasil: contribuições das Escolas Famílias Agrícolas. In: III Congresso de Estudos Rurais. 2007, Faro. Actas... III Congresso de Estudos Rurais. Faro: Universidade de Algarve, 2008, CD-ROM 3.

ROSSET, P. M. Mirando hacia el futuro: La Reforma Agraria y la Soberanía Alimentaria. AREAS Revista Internacional de Ciencias Sociales. La cuestión agraria: de los ilustrados a la globalización, n. 26 p.167-182, 2007.

SEVILLA- GUZMÁN, E. La Agroecología como estrategia metodológica de transformación social. Instituto de Sociología y Estudios Campesinos de la Universidad de Córdoba, España, p. 1-7, sem ano.

SEVILLA-GUZMÁN, E. Uma estratégia de sustentabilidade a partir da Agroecologia. Trad. CAPORAL, F. R. Agroecologia e desenvolvimento rural sustentável, v.2, n.1, 2001.

SEVILLA-GUZMÁN, E.; MOLINA, M. G. Sobre a evolução do conceito de campesinato. Trad. GUTERES, E.; CARVALHO, H. M. 3 ed., São Paulo: Expressão Popular, 2005.

WEZEL, A.; BELLON, S.; DORÉ, T.; FRANCIS, C.; VALLOD, D.; DAVID, C. Agroecology as a science, a movement or a practice. A review. Agronomy for Sustainable Development, v. 29, p. 503-515, 2009.

WOJTKOWSKI, P. A. Agroecological perspectives in agronomy, forestry and agroforestry. Enfield: Science Publishers Inc., 2002.

\section{Ensaio:}

Submetido em 31.07.2014

Aceito em 22.02.2015

R. Inter. Interdisc. INTERthesis, Florianópolis, v.12, n.1, p.337-360, Jan-Jun. 2015 